\title{
BIBLIOTECAS SEM FRONTEIRAS NO FOMENTO À LEITURA: O CASO DA BIBLIOTECA TRANSCOL ${ }^{1}$
}

\author{
Jorge Santa Anna \\ Mestrando do PPG Gestão e Organização do Conhecimento - UFMG \\ jorjao20@yahoo.com.br jorjao20@yahoo.com.br \\ Suelen de Oliveria Campos \\ Graduada em Arquivologia e Biblioteconomia \\ Especialista em Gestão de Projetos \\ suelen@gmail.com \\ Maria Aparecida de Mesquita Calmon
Graduadaem Biblioteconomia
cidamcalmon@hotmail.com
}

Resumo

Este estudo compreende os resultados finais de uma pesquisa, cuja temática contempla a missão de transcendência das bibliotecas no que se refere ao fomento à leitura. Objetiva apresentar o Projeto Biblioteca Transcol, demonstrando a oferta de material informacional disponibilizado em terminais rodoviários de grande circulação e disponíveis aos usuários que utilizam o sistema de transporte urbano da região metropolitana de Vitória, Espírito Santo. Metodologicamente, através de observação e aplicação de questionário, apresentamse as estruturas e os acervos dessa unidade, analisam-se as práticas de leitura e o perfil dos leitores, assim como a percepção dos usuários desses espaços quanto ao material fornecido e as condições ambientais para concretização da leitura. Concluiu-se que a leitura desenvolvida na referida unidade constitui um processo dinâmico, mutante, plural e prazeroso, com práticas de leitura diversificadas, tendo o leitor diferentes comportamentos durante a consolidação do ato de ler. Constatou-se que as leituras caracterizam-se como extensivas, no entanto, mesmo assim, os leitores não perdem a tendência contemplativa. Percebeu-se que os leitores estão satisfeitos e sendo despertados ao gosto e hábito pela leitura. Os entrevistados sugeriram como melhoria a diversificação quanto às modalidades de livros ofertados e a construção de um espaço específico para acomodar os leitores. Recomenda-se a ampliação desse projeto a outras estações de transporte da região, de modo a viabilizar uma sociedade cada dia mais leitora.

Palavras-chave: Leitura. Práticas de Leitura. Projeto Biblioteca Transcol. Perfil do leitor - Biblioteca Transcol. Bibliotecário - Papel Social.

\section{INTRODUÇÃO}

"A leitura transforma a vida das pessoas". Essa afirmação é muito conhecida na sociedade. Além de conhecida é comprovada a interferência da leitura na aquisição de conhecimentos dos sujeitos, tornando-os reflexivos, críticos, conhecedores e conscientes de suas atitudes, direitos e deveres em um contexto social.
Com base nesse poder da leitura, instituições sociais colocam-se a serviço de fomentar a prática da leitura, tendo em vista, sobremaneira, efetivar a prática cidadã. No âmbito governamental, a criação do Plano Nacional do Livro e Leitura (PNLL) revestese dessa causa, mobilizando ações em prol da promoção da leitura. Assim, torna-se uma tarefa conjunta, seja de pessoas, organizações e governo em unir esforços no sentido de 
promover parcerias e redes de leitura em todo o país (BRASIL, 2011).

A biblioteca, especialmente, como unidade provedora de informação, e os bibliotecários inserem-se nesse contexto, haja vista contribuírem com a prática da leitura. Diniz et al. (2011) destacam que os locais comumente utilizados para realização da leitura são a escola, a casa e a biblioteca. Santa Anna, Gregório e Gerlin (2014, p. 77) concordam com essa afirmação e acreditam que a leitura "[...] pode ser realizada em diferentes locais, não se limitando apenas aos ambientes residenciais, escolares ou de informação, como as bibliotecas [...]".

Essa preocupação com o incentivo à leitura impulsiona os bibliotecários a extravasarem os muros das bibliotecas, indo ao encontro de leitores. A esse respeito, o bibliotecário vem expandido suas atividades ao adquirir novas competências, "[...] ampliando sua atuação em ambientes que extrapolam os limites físicos da biblioteca. Com o propósito de viabilizar ações que fomentem o incentivo à leitura, esse profissional adquire a missão de agente educacional, cultural e social [...]" (SANTA ANNA; GREGÓRIO; GERLIN, 2014, p. 77).

Portanto, é pertinente que as bibliotecas realizem constantemente pesquisas e projetos voltados para fomentar a leitura. Além da elaboração e desenvolvimento dessas ações, faz-se necessário realizar monitoramentos a fim de consolidar melhoria contínua ao processo de leitura, investigando, por exemplo, as práticas de leitura, os comportamentos dos leitores, os produtos e serviços oferecidos, dentre outros aspectos.

A leitura precisa ser pesquisada, pois, segundo Chartier (1994, 1998), ela constitui um processo complexo que varia constantemente, sofrendo interferências de inúmeros fatores, como as tecnologias empregadas, os perfis dos leitores, além de questões estruturais e contextuais. Ainda, de acordo com a tese de Chartier (1998), ao analisar a trajetória do escrito, confirmou-se que a leitura não constitui uma prática estática e homogênea e nem, tampouco, existe uma regra única para se ler. A leitura em voz alta, de meditação e repetitiva, considerada como leitura intensiva; a leitura silenciosa e diversificada, denominada de leitura extensiva; como também a presença da leitura dinâmica provocada pela eletrônica constituem algumas das inúmeras formas de leitura que permearam (e permeiam) as sociedades humanas ao longo dos tempos.

Assim, este estudo disserta acerca dos espaços de leitura instituídos em locais externos às bibliotecas físicas, haja vista implementar ações de fomento à leitura na sociedade. Objetiva apresentar o Projeto Biblioteca Transcol, demonstrando a oferta de material informacional disponibilizado em terminais rodoviários de grande circulação e disponíveis aos usuários que utilizam o sistema de transporte urbano da região metropolitana de Vitória, Espírito Santo. Tendo em vista demonstrar o desenvolvimento do referido projeto, analisam-se as práticas de leitura e o perfil dos leitores ${ }^{2}$, assim como a percepção dos usuários desses espaços quanto ao material fornecido e as condições ambientais para concretização da leitura ${ }^{3}$.

\section{DIÁLOGO COM A LITERATURA}

No intuito de fundamentar as ideias propostas neste artigo acerca da importância da leitura e da contribuição do bibliotecário e da biblioteca no fomento a essa prática, principalmente quanto à elaboração de ações que estimulem essas práticas para além dos ambientes tradicionais das bibliotecas, esta seção destina-se a apresentar reflexões que confirmem a importância e necessidade em se realizar essas ações.

Assim, nos dois tópicos, a seguir, apresenta-se fundação teórica, considerando o papel da biblioteca e do bibliotecário no estímulo às práticas leitoras, como também os ambientes em que essa prática pelo se realizar e qual o comportamento dos leitores nos mais variados contextos e ambientes em que a leitura pode ser realizada.

\subsection{A CONTRIBUIÇÃO DAS INSTITUIÇÕES E PROFISSIONAIS NO FOMENTO À LEITURA: O PAPEL DA BIBLIOTECA E DO BIBLIOTECÁRIO}

A leitura vem sendo muito questionada ao longo dos tempos, principalmente a partir do momento que passou a ser vista como uma prática de transformação e desenvolvimento intelectual e social. É através da leitura que se desenvolve a habilidade crítica e reflexiva, o que torna o leitor capacitado a transformar 
sua realidade. Portanto, a leitura desperta o conhecimento do mundo, sendo um instrumento propagador de cidadania (MARINHO, 1993).

Por estar relacionada à cidadania, assim como defende a tese de Marinho (1993), a leitura torna-se objeto de preocupação de governantes, principalmente nos países de sistema democrático. Ela ocupa (ou deveria ocupar) um lugar privilegiado nos planos governamentais, o que justifica a criação de políticas públicas que assegurem a formação de uma sociedade leitora (ROSA; ODDONE, 2006).

Para que a sociedade se torne leitora, não basta apenas investir no sistema educacional, de modo a reduzir o analfabetismo. É preciso, segundo Rosa e Oddone (2006), implementar programas de incentivo à leitura, sendo necessário, também, demonstrar a importância do livro e das instituições que se colocam a serviço de sua guarda e disseminação, como as bibliotecas.

Especificamente, no Brasil, observa-se um cenário desigual e contraditório, pois, ao mesmo tempo em que há políticas públicas e programas governamentais em favor da leitura, do livro e das bibliotecas, muitas medidas não são implementadas, o que transforma o país em uma nação com poucos leitores (ROSA; ODDONE, 2006).

Segundo essas autoras, transformar o Brasil em um país de leitores constitui um grande desafio, principalmente com os reflexos da sociedade da informação, em que novos suportes informacionais surgem, o que demanda conhecimento no uso das novas tecnologias por parte do leitor, e isso pode acarretar novos problemas na tentativa de incluir o cidadão nesse novo estágio da sociedade.

Mesmo diante dessas dificuldades, é preciso considerar que a luta por uma sociedade leitora não constitui apenas missão dos governos, mas também de outras instituições e profissionais engajados com as causas sociais. Trata-se de um trabalho conjunto, em que esforços devem ser comungados, assim como dispõe o PNLL, cuja meta principal é criar condições favoráveis para a formação de leitores e o incentivo à leitura no Brasil (BRASIL, 2011).

De acordo com o referido programa, todo cidadão deve ter acesso ao livro e à leitura, independente de quaisquer limitações desse sujeito. Portanto, esse programa coloca-se a serviço da formação cidadã por meio da prática da leitura. Santa Anna, Gregório e Gerlin (2014, p. 79), a respeito do PNLL, consideram que

O documento legal determina que o país condicione a formação continuada de profissionais, seja das escolas, seja das bibliotecas. Para atingir esse fim, deve ser viabilizada a produção e distribuição de materiais de orientação, com vistas a promover parcerias e redes de leitura. Também se recomenda no texto legal a ampliação e implementação de bibliotecas escolares e dotação de acervos.

Considerando as reflexões dos autores citados, entende-se que as instituições educacionais, como as escolas $\mathrm{e}$ as bibliotecas, devem ser disseminadoras e incentivadoras das práticas leitoras. Os profissionais dessas instituições devem comportar-se como agentes educacionais, culturais e sociais, tendo apoio, incentivo e investimento por parte das autoridades governamentais.

Assim, é necessário repensar o papel da biblioteca, a qual deve adquirir uma dimensão educativa, como mediadora e formadora de leitores (prática de leitura), além de sua atuação como agência modificadora " [...] do viver, do sentir e do pensar do indivíduo, ou seja, torná-los verdadeiramente cidadãos" (MARINHO, 1993, p. 93).

Sendo assim, depreende-se o importante papel que o bibliotecário possui quanto à formação de uma sociedade leitora. Esse profissional não pode ser visto apenas como guardião dos acervos, mas sim, como propagador da informação, contribuindo para o desenvolvimento cidadão, tendo em vista conquistar " [...] igualdade de oportunidades sociais que possibilitem a todos os estudantes o acesso ao conhecimento registrado" (CALDIN, 2005, p. 163).

Com efeito, o bibliotecário deve ser dinâmico e audacioso, desenvolvendo ações que interfiram no cotidiano das pessoas. No que se refere ao incentivo à leitura, não resta dúvida de que, a inovação e criatividade são primordiais para atrair os novos leitores. $\mathrm{O}$ bibliotecário deve fazer com que a biblioteca seja um espaço divertido e agradável para que as pessoas tenham mais vontade de frequentála. Projetos podem ser realizados nas 
unidades de informação para atrair e manter os leitores interessados (PITZ; SOUZA; BOSO, 2011).

A adoção de projetos constitui uma forma valiosa para divulgar o trabalho prestado na unidade de informação. Portanto, no que se refere à leitura, o desenvolvimento de projetos que viabilizem o contato dos usuários com os materiais informacionais, que despertem o interesse pela leitura, tais como dramatizações e contações de história constituem atividades criativas e inovadoras (PITZ; SOUZA; BOSO, 2011).

Outro exemplo de atividades bibliotecárias criativas e inovadoras voltadas à propagação da leitura diz respeito à construção de espaços de leitura, podendo esses espaços serem estruturados fora do ambiente interno da biblioteca, o que permite uma atuação bibliotecária além da biblioteca (SANTA ANNA; GREGÓRIO; GERLIN, 2014).

É evidente que os espaços de leituras criados fora da estrutura física da biblioteca ampliam os laços de aproximação entre biblioteca e sociedade. Para Santa Anna, Gregório e Gerlin (2014), essa atuação é, sem dúvida alguma, uma atitude interventiva do bibliotecário, haja vista despertar a importância e o interesse pela leitura a um número cada vez maior e diversificado de leitores. Assim, projetos podem ser realizados no sentido de implementar espaços de leitura em diversos locais de uma comunidade, seja em locais públicos de grande circulação, seja em locais mais reservados e privativos, como no interior de empresas.

\subsection{ALÉM DOS MUROS DAS BIBLIOTECAS: OS ESPAÇOS E PRÁTICAS DE LEITURA E O PERFIL DO LEITOR}

Considerando a atuação da biblioteca além de seu recinto, no que se refere à propagação da leitura, assim como apontou Santa Anna, Gregório e Gerlin (2014), ao estruturarem um espaço de leitura em instituição hospitalar, depreende-se que a biblioteca e demais instituições educacionais devem ser um organismo dinâmico que vai ao encontro da sociedade, desenvolvendo um trabalho interventivo e de mudanças.

Marinho (1993) reforça o trabalho árduo das escolas e bibliotecas na busca por uma sociedade leitora. Segundo esse autor, no que se refere à biblioteca, essa unidade possui um caráter social, e não pode se manter isolada, nem tampouco, restrita a atividades internas de seu recinto. Ao contrário, ela deve extravasar suas paredes, indo ao encontro de leitores e promovendo ações que fomentem a leitura em todas as partes e grupos da sociedade.

A biblioteca possui inúmeras contribuições e funcionalidades na sociedade, sendo a propagação da leitura, uma de suas maiores responsabilidades. Mas essa missão não deve restringir-se aos muros das unidades. Ao contrário, as atividades bibliotecárias devem atingir diferentes contextos e instâncias (SANTA ANNA, GREGÓRIO, GERLIN, 2014). E, essa expansão torna-se ainda mais fácil com o uso das novas tecnologias, em que a biblioteca torna-se universal, sem muros e até sem lugar específico, o que permite a propagação da biblioteca na sociedade (CHARTIER, 1994).

Promover ações de leitura em ambientes externos às instituições educacionais requer a gestão de espaços específicos para acomodar os materiais informacionais, assim como proporcionar condições físicas e adequadas ao leitor para que o processo de leitura se efetive. Os espaços de leitura, segundo Barreto (2007, p. 44-45), apresentam-se "[...] como o lugar, o ambiente destinado ao ato de ler, onde o corpo do leitor presentifica-se $[\ldots] "$.

Por isso, ao se pensar nos espaços de leitura, segundo Santa Anna, Gregório e Gerlin (2014), deve-se considerar essas estruturas como locais que viabilizam a aprendizagem. Portanto, segundo esses autores, a prática da leitura não pode ser realizada apenas em ambientes educacionais, na família ou na biblioteca. Nesse contexto, entende-se que a leitura pode ser realizada por meio da estruturação de ambientes de aprendizagem "[...] organizados fora do ambiente escolar e/ou da biblioteca, podendo ser firmada em ambientes onde o público aproveita o tempo ocioso para consolidação da leitura" (SANTA ANNA, GREGÓRIO, GERLIN, 2014, p. 85, grifo nosso).

Assim, no entendimento desses autores, constata-se que o bibliotecário expande sua atuação profissional e cumpre sua missão de agente cultural e social ao adquirir competência informacional, contribuindo, 
sobremaneira, no gerenciamento desses espaços destinados à leitura e aprendizagem.

Embora pareça um processo simplista, ao arquitetar um espaço de leitura, muitas questões complexas estão envolvidas, assim como defendeu Chartier e Lebrun (1998). O ambiente que está à volta do leitor, as condições estruturais oferecidas para acomodar esse sujeito são fatores interferentes nas técnicas utilizadas por ele durante a realização da leitura. Esses autores também demonstram que o espaço físico, assim como as tecnologias que materializam os textos (os suportes) são questões que repercutem na produção de sentido.

No que se refere às tecnologias utilizadas, é consenso na literatura que os recursos informáticos viabilizam grandes mudanças no processo de leitura, assim como na definição do perfil do leitor e sua interação com o texto lido e produção de sentidos. Nesse enfoque das novas tecnologias, evidencia-se que esses suportes provocam mutações nas práticas de leitura, e o uso da eletrônica como forma de escrita e comunicação acentuou a capacidade de interação do texto com o leitor, por conseguinte, aumentaram-se as técnicas e práticas de leitura na sociedade atual, viabilizando, também, diferentes perfis de leitores (SANTA ANNA; PEREIRA, 2014). Sendo assim, não resta dúvida de que "a revolução do texto eletrônico será, ela também, uma revolução da leitura. Ler num monitor não é o mesmo que ler num códice [...]" (CHARTIER, 1994, p. 190).

Vê-se que a trajetória do escrito ao longo dos tempos é suficiente para demonstrar a pluralidade de formas que podem ser utilizadas para a prática da leitura, o que demonstra ser a leitura um processo dinâmico, mutante e plural (CHARTIER, 1994). Portanto, as práticas, técnicas e metodologias de leitura existentes são das mais diferenciadas, tendo o leitor a oportunidade de optar por um ou outro tipo, considerando questões espaciais, tecnológicas e contextuais (CHARTIER; LEBRUN, 1998).

Levando em consideração essas questões que permeiam o contexto do leitor, nota-se a consolidação de diferentes perfis de leitores. A esse respeito, refletem Santa Anna e Pereira (2014, p. 1693):

O surgimento da escrita representa um grande marco histórico à leitura, condicionando o surgimento de diferentes práticas de leitura ao longo do desenvolvimento das sociedades. É graças aos recursos materiais ou suportes tecnológicos que a escrita pôde ser representada graficamente, por conseguinte, diversificaram-se as técnicas, estratégias e metodologias de se realizar a leitura, acarretando, outrossim, perfis diferenciados de leitores.

Assim, as diversas técnicas de leitura viabilizadas ao longo dos tempos repercutem na formação do leitor contemporâneo, o qual deixa de ser um agente receptor, para ser um interagente, assumindo um papel mais dinâmico e participativo na construção dos significados oriundos do texto. Logo, diferentes técnicas de leitura podem ser utilizadas, caracterizando diversos perfis de leitor que podem ser: contemplativo (que realiza leitura detalhada), movente (o qual utiliza variadas fontes) ou imersivo (utiliza fontes contextualizadas com recursos da internet) (SANTAELLA, 2004).

Em suma, observam-se as complexidades que envolvem os espaços de leitura, logo, confirma-se a importante missão do bibliotecário ao arquitetar e gerenciar esses ambientes, sendo necessário constante monitoramento das condições estruturais e contextuais e dos recursos que permitem que a prática da leitura seja realizada e disseminada de forma efetiva na sociedade.

\section{MÉTODO DA PESQUISA}

A metodologia utilizada no desenvolvimento deste estudo caracterizou a pesquisa como descritiva, no que se refere aos objetivos do estudo e pesquisa de campo, no que se refere aos procedimentos técnicos utilizados.

Consideramos este estudo como descritivo, pois ele analisou a realidade de uma dada população, ou seja, 32 usuários que frequentam os espaços de leitura estruturados em terminais rodoviários, espaços esses denominados de Biblioteca Transcol. Também pode ser considerado como descritivo, uma vez que utilizou como técnica de coleta de dados, formulário com perguntas fechadas (11 perguntas).

No caso deste estudo, o ambiente de pesquisa delimitado foi $o$ projeto desenvolvido por uma instituição 
bibliotecária, denominado de Projeto Biblioteca Transcol, cujo objetivo desse projeto é disponibilizar acervos de livros para leitores que frequentemente utilizam $o$ sistema de transporte coletivo, sendo esses acervos caracterizados como espaços de leitura inseridos nos terminais rodoviários pertencentes ao sistema de transporte coletivo.

Quanto às técnicas para coleta de dados, utilizou aplicação de questionário a leitores das Bibliotecas Transcol, bem como o estudo de observação junto aos bibliotecários que gerenciam o projeto, com o intuito de coletar informações sobre a criação, desenvolvimento e monitoramento do projeto.

No que se refere à abordagem do problema, este estudo classifica-se como quali-quantitativo, pois ao mesmo tempo que se analisam dados concretos e objetivos com base nas respostas obtidas na aplicação do questionário, recorreu-se à indução, a partir das entrevistas com os bibliotecários, bem como às reflexões oriundas da fundamentação teórica.

\subsection{O PROJETO BIBLIOTECA TRANSCOL}

Tendo em vista a fundamentação teórica discorrida, considera-se a Biblioteca Transcol como um espaço de leitura gerenciado pela Biblioteca Pública do Estado do Espírito Santo, em parceria com a Companhia de Transportes Urbanos da Grande Vitória (CETURB), empresa essa que gerencia o sistema de transporte coletivo unificado dessa região, denominado de Sistema Transcol.

Esse sistema adota a estrutura troncoalimentadora, interligando diferentes linhas em diversos terminais rodoviários, dispersos nos cinco municípios que compõem a região metropolitana. Atualmente, o sistema possui um total de dez terminais interligados, com local destinado ao embarque e desembarque de passageiros. No interior dos terminais também há diferentes lojas que prestam diversos serviços e/ou oferecem produtos variados aos usuários que utilizam o sistema.

Levando em consideração a quantidade de pessoas que circulam nesses locais diariamente e o tempo gasto na viagem dentro dos ônibus ou na espera nos terminais, foi instituído um acervo contendo diferentes literaturas, tendo em vista incentivar a prática da leitura, durante a permanência das pessoas nos terminais ou dentro dos coletivos.

Esses acervos foram expostos em prateleiras, no interior de uma sala, a qual possui também computadores com acesso à internet. Esses espaços, denominados de Biblioteca Transcol, estão presentes em todos os terminais da Grande Vitória. Logo, o sistema consta com um total de dez acervos.

Cada unidade possui em média um total de, aproximadamente, 1400 itens informacionais (no caso, livros impressos). Esses acervos constam com diversas literaturas, seja ela científica, acadêmica ou literária. No entanto, a maior parte do acervo está composta por obras de literatura.

Os serviços prestados nesses espaços envolvem desde a consulta local aos materiais, bem como o empréstimo domiciliar, podendo o usuário ler o livro dentro dos terminais enquanto espera os ônibus, ou dentro dos ônibus durante $\mathrm{o}$ trajeto, ou até mesmo, em sua residência.

A figura 1 ilustra o interior das unidades, com destaque à disponibilização dos livros nas estantes, computador para uso e balcão de empréstimo.

Figura 1 - Interior da Biblioteca Transcol 


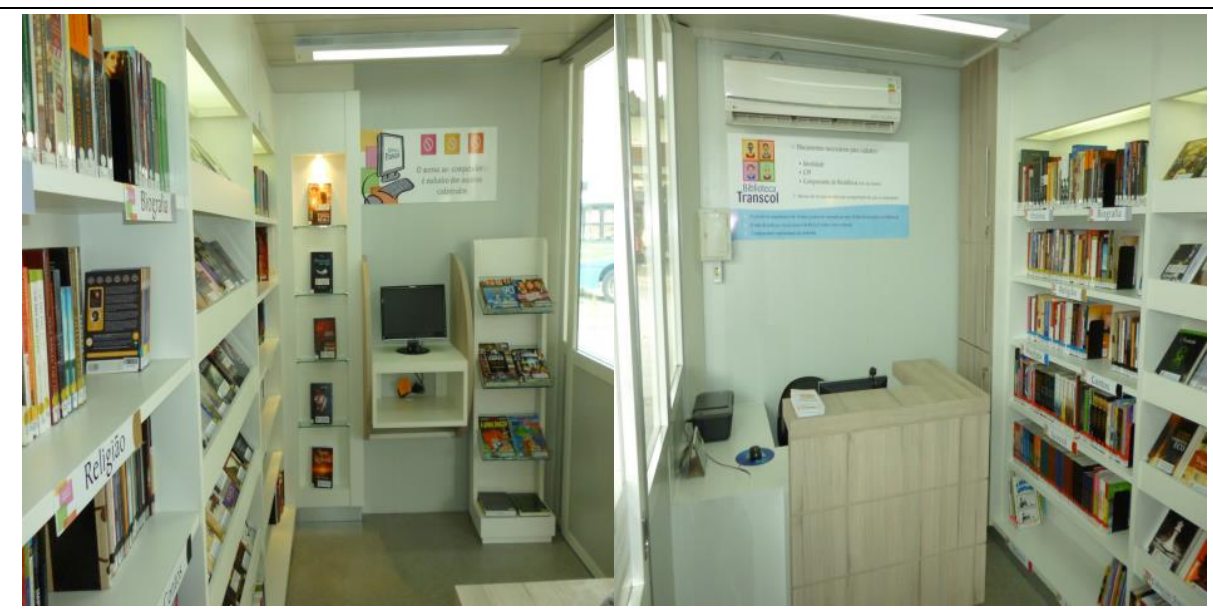

Fonte: Universidade para todos (2014).

Portanto, o projeto intitulado "Biblioteca Transcol" sustentou-se através das ações voltadas à instalação de unidades de locação de livros, nos terminais rodoviários do Sistema Transcol, pois, nesses circulam parcela significativa do público-alvo do projeto. Os interessados se cadastram nas próprias bibliotecas, retiram a carteirinha de associado na mesma hora, e podem locar, gratuitamente, um livro por vez, pelo período de dez dias. Nesse sentido, o projeto está incentivando a leitura e contribuindo para a melhoria do nível de informação e conhecimento das populações menos favorecidas.

Fiel ao objetivo delimitado neste estudo, serão analisados, a seguir, os dados coletados em campo, a partir da aplicação de questionário a 32 usuários-leitores das Bibliotecas Transcol. Entre nove bibliotecas foram entrevistados três leitores em cada uma delas, abordados aleatoriamente no momento da coleta dos dados. Em apenas uma biblioteca, por ela ser maior, entrevistou-se um total de cinco leitores, também abordados aleatoriamente.

Tendo em vista demonstrar o desenvolvimento do referido projeto, o questionário foi sistematizado de modo a contemplar três diferentes aspectos, que são: 1 - as práticas de leitura adotadas pelos leitores desse sistema; relacionado ao primeiro aspecto, 2 - o perfil desses leitores; e, 3 - a percepção dos usuários desses espaços quanto ao material fornecido e as condições ambientais para concretização da leitura.

\subsection{RESULTADOS E DISCUSSÃO}

\subsubsection{As práticas, técnicas e estratégias de leitura realizadas na Biblioteca Transcol}

Na opinião dos 32 leitores entrevistados, no que se refere ao local mais adequado para concretização da leitura, as opiniões se divergem. Para três leitores $(9,4 \%)$, realizam a leitura dentro dos ônibus, durante os trajetos; para dois leitores $(6,2 \%)$, o local que mais lê é nos terminais, quando estão à espera dos ônibus; já para 13 leitores $(40,6 \%)$, a leitura é realizada em casa, enquanto que para 14 leitores $(43,75 \%)$, a leitura é realizada em diferentes locais, seja em casa, nos ônibus ou nos terminais (gráfico 1 ).

Gráfico 1 - Local em que os leitores realizam a leitura

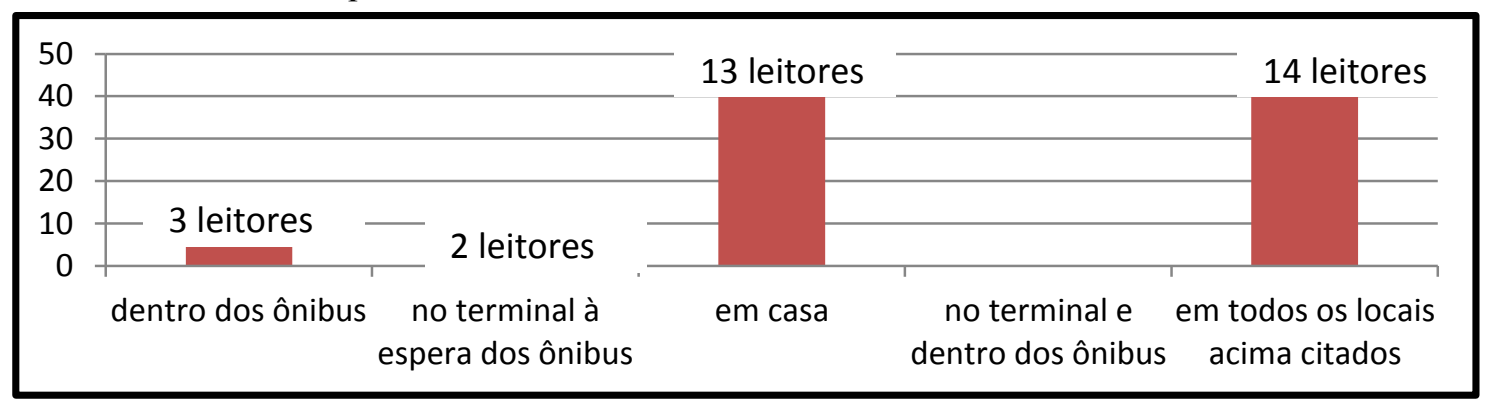

Fonte: dados da pesquisa (2016). 
Percebe-se que a maioria dos entrevistados realiza o processo de leitura em qualquer local, desde que haja condições para tal, ou seja, que o leitor esteja com tempo ocioso, tendo a leitura um papel de complementação, assim como afirma ScliarCabral (2009), de que, a leitura exerce influência sobre a mente. Assim, segundo essa autora, lê-se para ocupar a mente, uma forma de aproveitar o tempo para adquirir novos conhecimentos e despertar o exercício mental.
Quando se indagou a respeito das técnicas, metodologias ou estratégias específicas que os leitores utilizam, haja vista tornar $\mathrm{o}$ processo mais agradável $\mathrm{e}$ compreensível, constatou-se que, para dez leitores $(31,25 \%)$, prefere-se ler por capítulos, o que viabiliza maior organização das ideias; já para 12 leitores $(37,5 \%)$, realiza-se a leitura até que haja cansaço; por fim, novamente dez leitores $(31,25 \%)$ disseram que leem enquanto estão com o tempo ocioso (gráfico 2).

Gráfico 2 - Técnicas utilizadas no discorrer da leitura

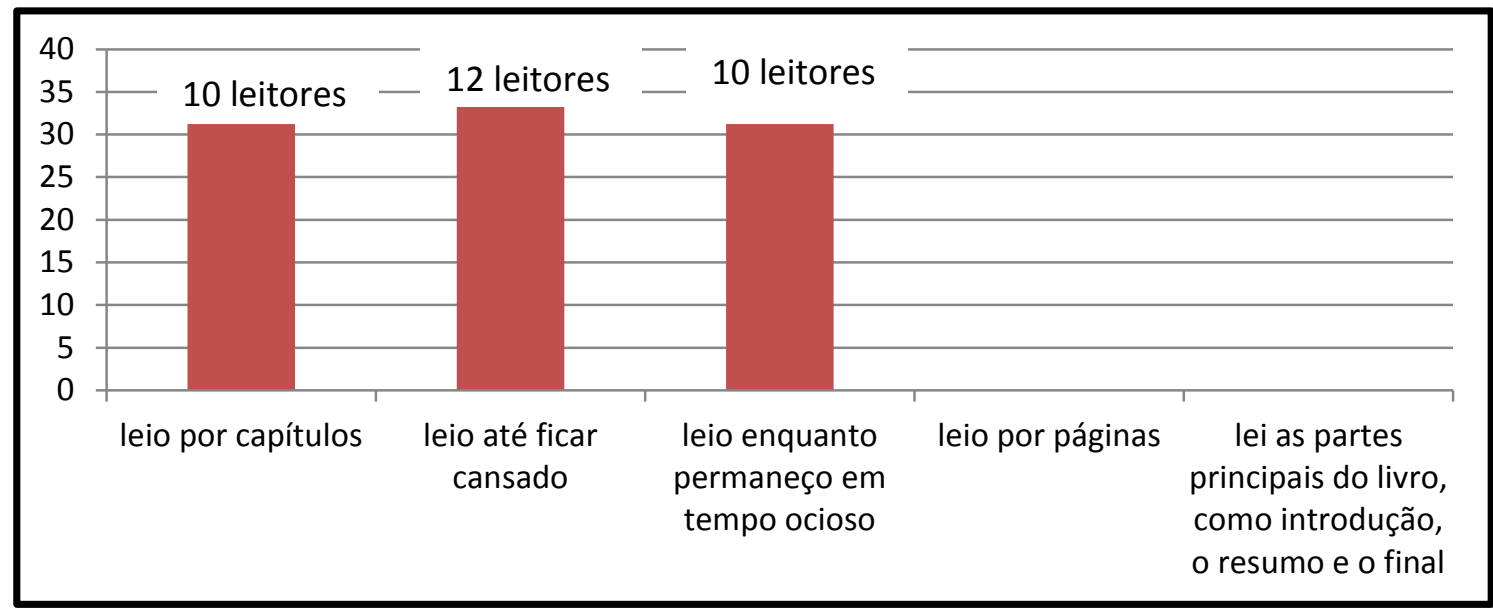

Fonte: dados da pesquisa (2016).

Percebe-se que a maioria dos leitores são verdadeiros "devoradores" de livros, pois leem até aparecer o cansaço, ou seja, continuam lendo um texto desde que estejam conseguindo assimilar as ideias. Nesse enfoque, dialogamos com Chartier (1998) ao mencionar Michel de Certeau, destacando que o leitor nada mais é do que, um caçador que percorre terras alheias. Constatamos que a maioria dos leitores da Biblioteca Transcol leem por prazer, tornando-se verdadeiros caçadores de novas ideias dispersas nas linhas e entrelinhas escritas por um autor.

Perguntou-se, também, no âmago das práticas de leitura, a respeito da interação entre o leitor e o suporte que materializa a escrita, nesse contexto, o livro impresso. Investigou-se a respeito da utilização de recursos ou instrumentos auxiliares de modo que o processo de leitura fosse melhor desenvolvido. Assim, para oito leitores (25\%), utiliza-se tampão de ouvido; para cinco leitores $(15,6 \%)$, prefere-se o uso da régua para delimitação das linhas do texto; também cinco leitores preferem ler ouvindo música baixa; já dez leitores (31,25\%) utilizam o dedo indicador como ponto de marcação das linhas e palavras; por fim, apenas quatro leitores $(12,5 \%)$ disseram ler sem o auxílio de nenhum recurso (gráfico 3 ).

Gráfico 3 - Utilização de recursos para melhorar o desenvolvimento da leitura 


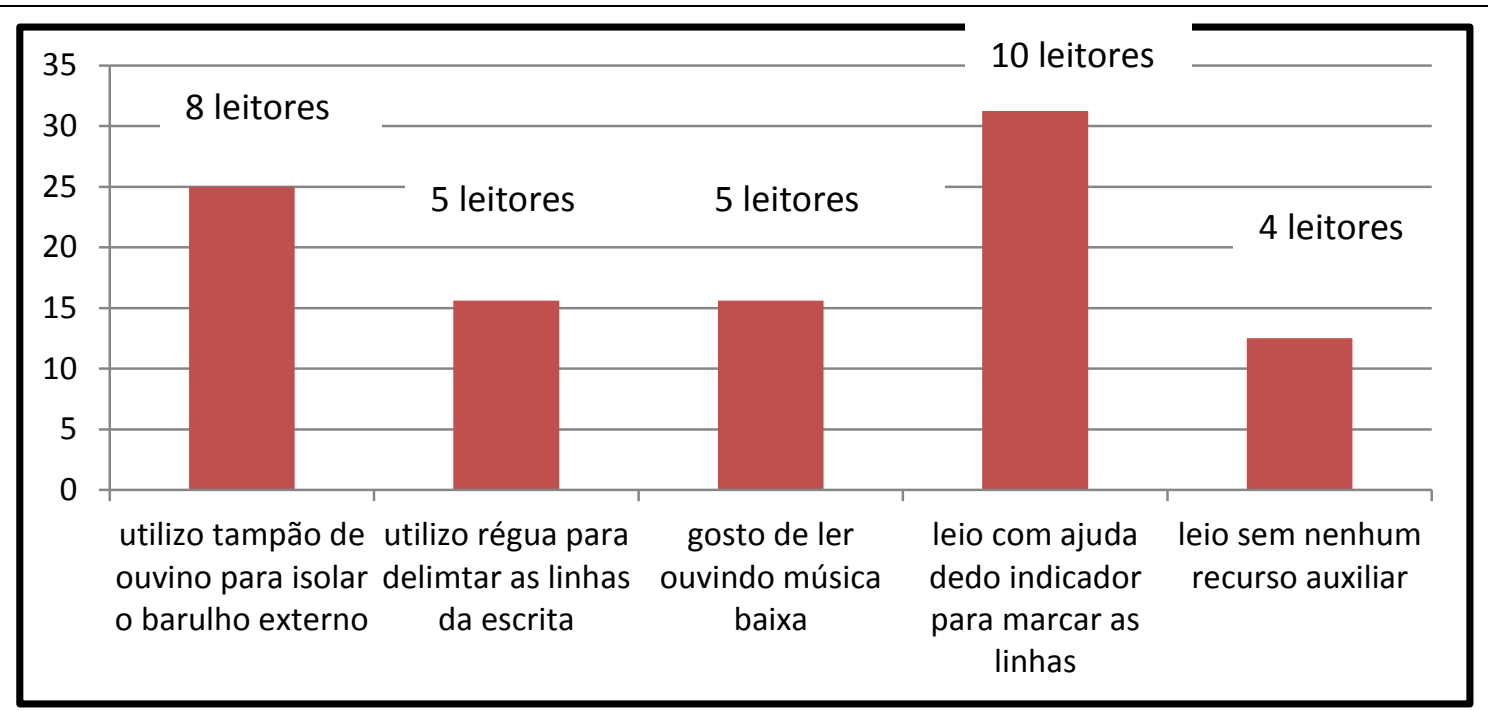

Fonte: dados da pesquisa (2016).

De acordo com os dados obtidos do gráfico acima, resulta-se que há forte interação entre texto e leitor, assim como defendeu Chartier (1994), de que o texto, como produto da escrita, e o leitor estabelecem uma interação, podendo essa ser voltada ao sentido do texto (concentração) quanto ao contato, considerando as tecnologias envolvidas no suporte textual.

$\mathrm{O}$ dedo indicador aparece como o recurso mais utilizado para facilitar a leitura e a grande minoria não utiliza nenhum recurso. Curioso que alguns leitores preferem ler ouvindo música, já outros optam pelo silêncio absoluto. Esses resultados confirmam as teorias de Chartier (1994, 1998), quando menciona que, ao longo dos tempos, inúmeras práticas de leituras vêm sendo utilizadas, desencadeando perfis diferenciados de leitor, um processo integralmente dinâmico e diversificado.

No entendimento de Hillesheim et al. (2011), é importante mencionar que o texto se constrói no encontro com o leitor, na relação entre um e outro. Portanto, é evidente que não se pode dissociar texto e leitor, e nessas relações em que cada leitor possui sua estratégia, sobretudo com os diversos suportes que registram a escrita, é comum que, constantemente, sejam manifestadas novas e adversas combinações.

\subsubsection{O perfil dos leitores das bibliotecas Transcol}

A princípio, investigou-se a quantidade e tipologia de livros utilizados pelos leitores. No que se refere à quantidade de livros em que se realiza a leitura por mês, oito entrevistados $(25 \%)$ leem apenas um livro; 11 usuários $(34,4 \%)$ leem um total de dois livros; três respondentes $(9,4 \%)$ leem três livros; e dez usuários leem quatro livros ou mais a cada mês (gráfico 4).

Gráfico 4 - Quantidade de livros lida mensalmente pelos usuários da Biblioteca Transcol.

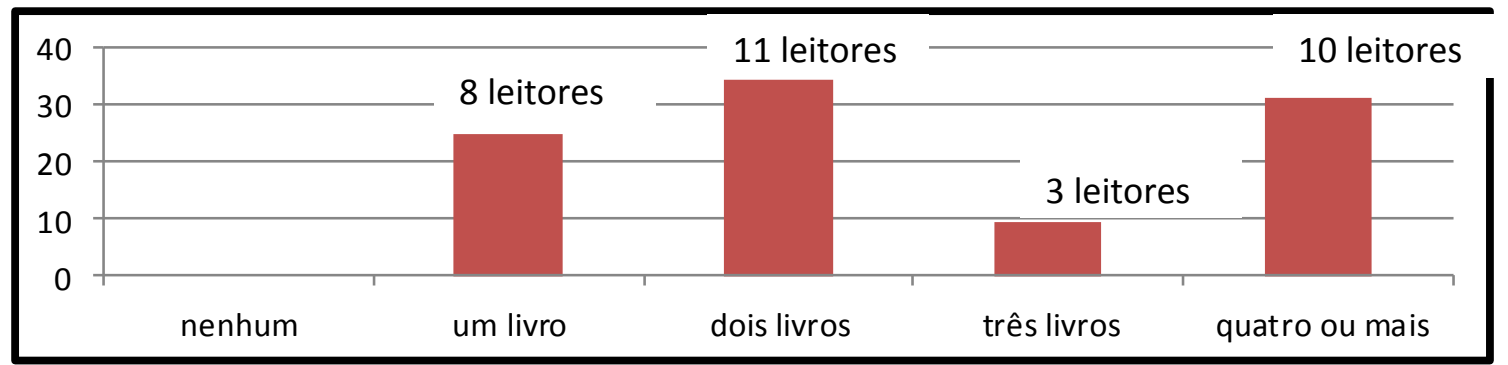

Fonte: dados da pesquisa (2016). 
Quanto às modalidades de literatura lidas pelos usuários, obteve-se que, a grande maioria, 26 leitores $(81,25 \%)$ procura por romance; dois leitores $(6,25 \%)$ preferem ler livros de autoajuda; três leitores $(9,37 \%)$ escolhem a literatura acadêmica; e, por sua vez, apenas um leitor $(3,12 \%)$ lê todas as modalidades de literatura mencionadas no questionário (gráfico 5).

Gráfico 5 - Modalidade de literatura utilizada pelos usuários da Biblioteca Transcol.

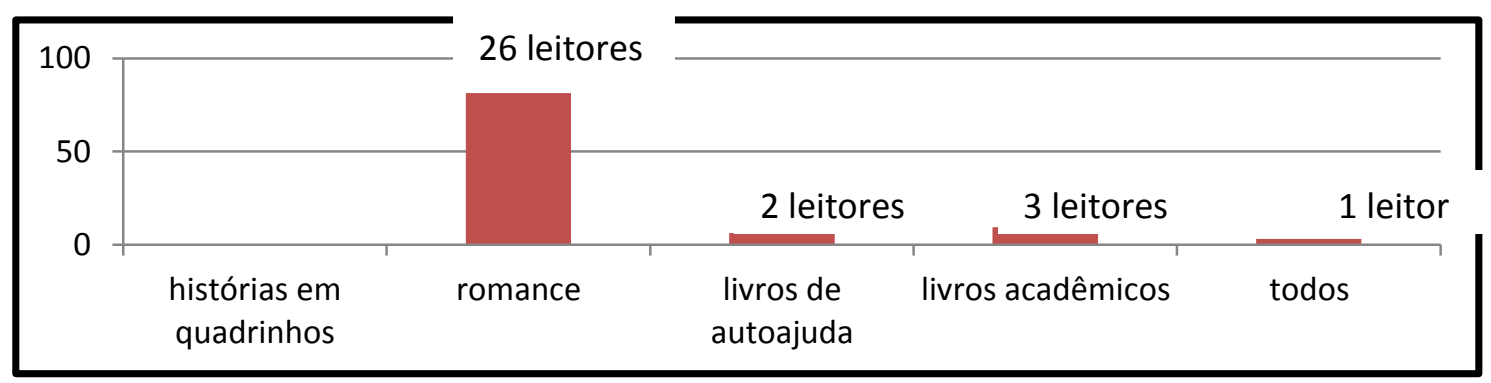

Fonte: dados da pesquisa (2016).

Por meio da análise aos dois gráficos supracitados, entende-se que o público da Biblioteca Transcol é um público leitor, sendo que boa quantidade lê quatro livros ou mais por mês, o que afere um resultado significativo. O tipo de obra mais procurada é $\mathrm{o}$ romance, seguido por livros acadêmicos e de autoajuda.

Recorrendo às reflexões de Chartier (1994, 1998), a partir desses dados, é importante discorrer acerca da leitura silenciosa e extensiva, muito comum nas sociedades modernas, ao contrário do que ocorria na sociedade antiga e medieval, em que se optava pela leitura em voz alta e intensiva. Segundo o referido autor, essa mudança de um tipo de leitura para outra, é consequência provável do crescimento editorial, o qual proporcionou mais facilidade de acesso ao livro e à leitura, permitindo que as pessoas lessem individualmente (leitura silenciosa) e uma maior quantidade de livros (leitura extensiva).

O leitor do sistema Transcol realiza a leitura para diversos fins. De acordo com os dados obtidos na pesquisa, a maioria, 10 respondentes $(31,25 \%)$, realiza a leitura em casa com fins de entretenimento; cinco leitores $(15,6 \%)$, leem nos ônibus e terminais por necessidades profissionais; oito leitores (25\%) leem nos ônibus e terminais a fim de aproveitar o tempo de espera; outros oito leitores (25\%) leem em casa a fim de adquirem conhecimentos; e, por fim, apenas um leitor $(3,12 \%)$ considera que lê por outros motivos (gráfico

$6)$.

Gráfico 6 - Motivo que leva o leitor a utilizar os livros ofertados pela biblioteca Transcol 
Relatos de Pesquisa

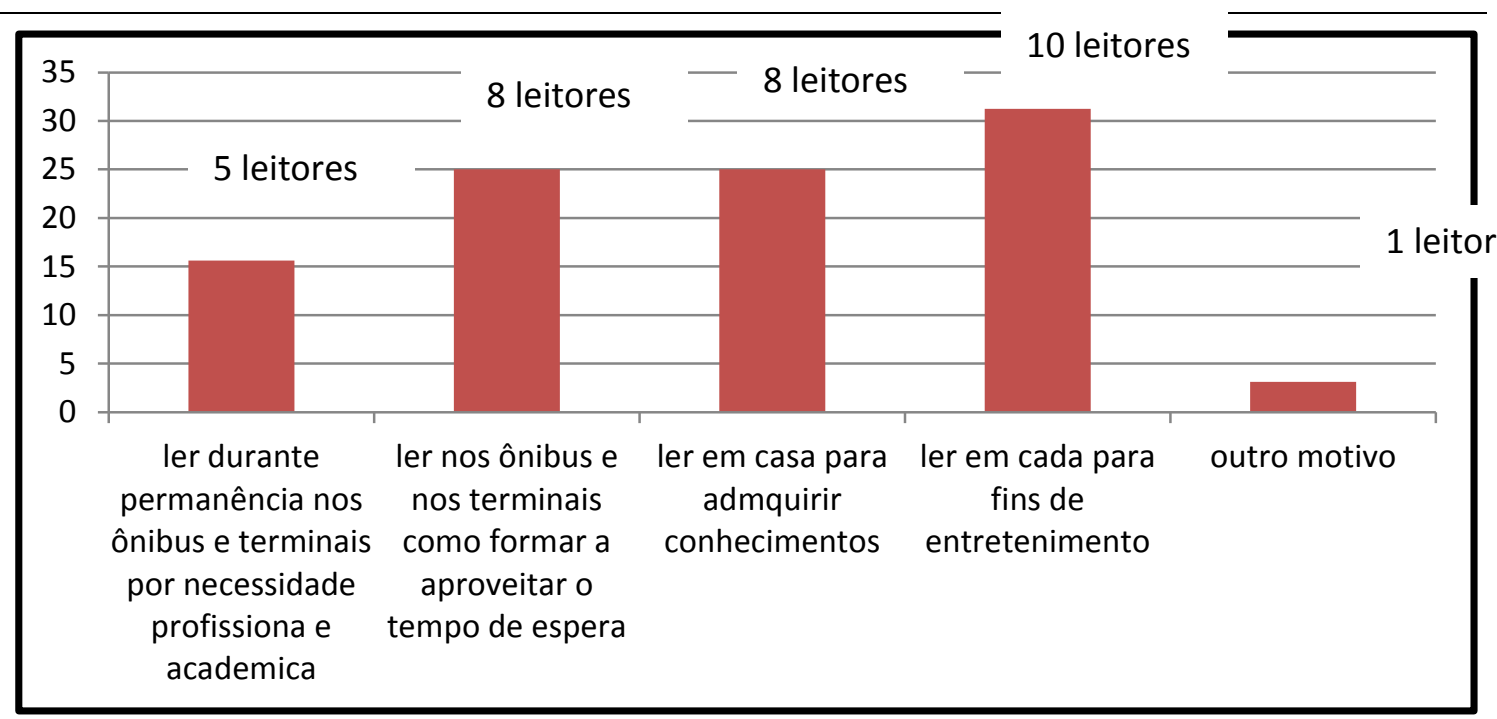

Fonte: dados da pesquisa (2016).

Esse resultado vai ao encontro do que afirma Brito (2010), de que o leitor busca na leitura diversos objetivos, tanto de cunho informacional, quanto para se instruir, obter e aprofundar conhecimentos, entretenimento, prazer, por gosto, comunicabilidade e para melhor compreender o meio em que se vive. Enfim, o sujeito busca na leitura sua satisfação em meio a diferentes necessidades.

A figura do leitor aparece no contexto atual repleto de mudanças, como um agente que sofre interferências de inúmeros fatores externos durante o processo de leitura, fato esse que pode viabilizar o desvio no real sentido de um texto quando idealizado por seu autor, no momento que é decodificado pelo processo de leitura (CHARTIER; LEBRUN, 1998).

Para os leitores do Transcol, a maioria, 15 leitores $(46,9 \%)$, recebe interferências de vários fatores externos, como: barulho, luminosidade e postura em pé; para cinco entrevistados $(15,6 \%)$, o fator mais presente é o barulho; para 11 leitores $(34,5 \%)$, o principal fator diz respeito à postura em pé; $\mathrm{e}$, ao final, para apenas um leitor $(3,12 \%)$, não existem fatores interferentes (gráfico 7).

Gráfico 7 - Fator mais presente no cotidiano dos leitores da Biblioteca Transcol

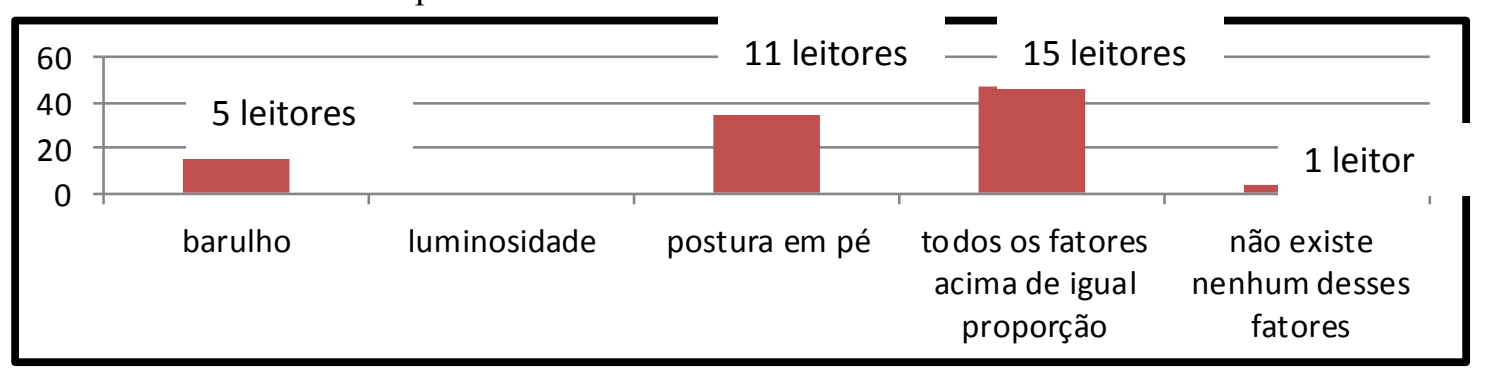

Fonte: dados da pesquisa (2016).

Essas interferências nos remetem a afirmar que a leitura constitui um processo dinâmico, complexo e subjetivo, conduzida e refletida única e exclusivamente pelo leitor que dela se apropria, sendo expressa por meio de "[...] um gesto, individual ou coletivo, dependente das formas de sociabilidade, das representações do saber ou do lazer, [e] das concepções da individualidade" (CHARTIER, 1994, p. 173). 
Os fatores externos aliados ao texto refletem diferentes ambiências, o que proporciona diferentes modalidades de leitor. $\mathrm{Na}$ visão de Santaella (2004), na modernidade, existem três categorias de leitores: o contemplativo, o movente e o virtual. De acordo com os leitores entrevistados, a maioria, 20 sujeitos $(62,5 \%)$, acredita que a ambiência proporcionada pelo Sistema Transcol favorece a consolidação de um leitor contemplativo; para cinco leitores $(15,6 \%)$, são leitores moventes; também cinco acham que são leitores imersivos; e por fim, apenas um respondente $(3,12 \%)$ considera ser outro tipo de leitor (gráfico 8 ).

Gráfico 8 - Tipos de leitor, dadas as condições ofertadas pelas Bibliotecas Transcol

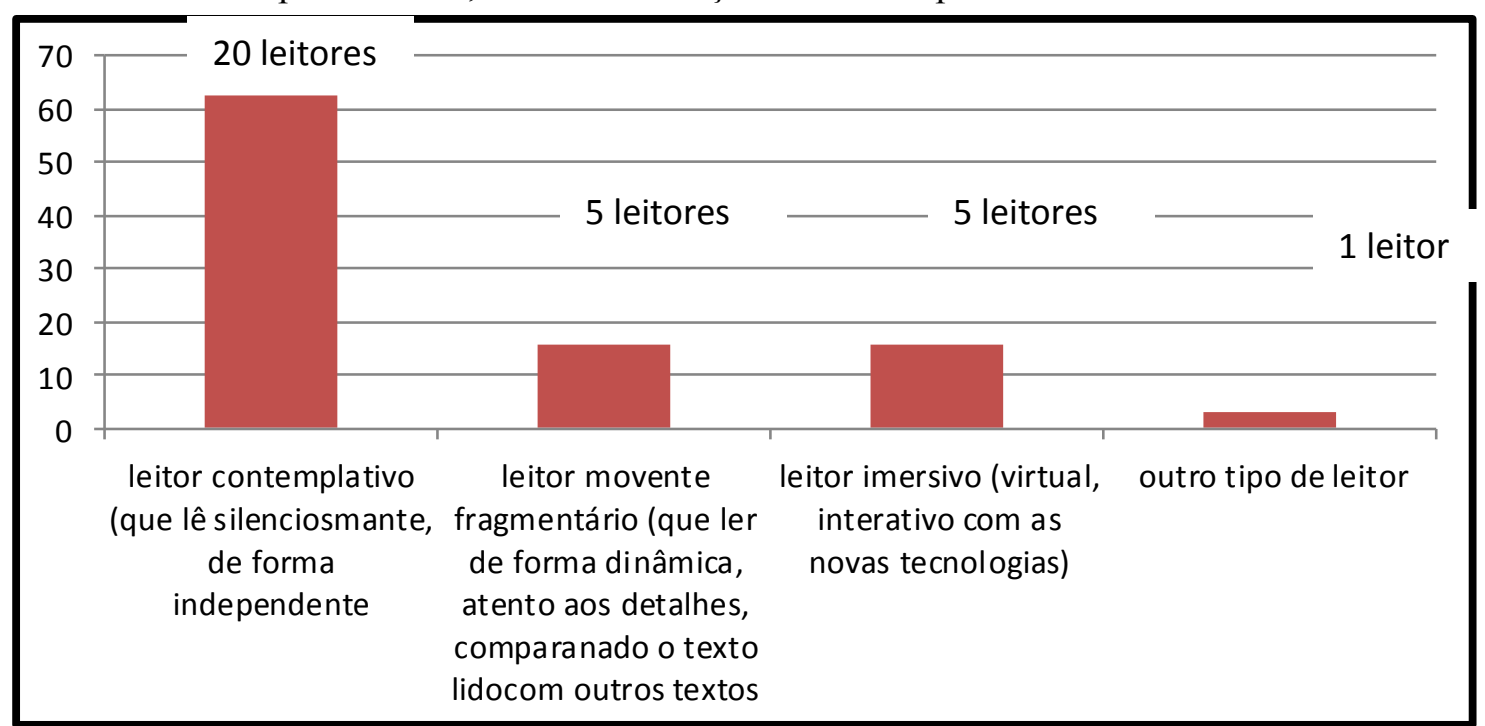

Fonte: dados da pesquisa (2016).

Não resta dúvida de que o texto lido em voz alta ou de forma silenciosa, bem como o texto materializado em tabletes de argila, papiro, pergaminho ou impresso em papel, assim como, a ambiência e contexto ideológico na qual o leitor se situa despertam no leitor a transposição de um mundo imaginário (registrado no suporte) a um mundo real (contextualizado) (CHARTIER; LEBRUN, 1998).

A partir desse conjunto de fatores que permeiam a ambiência social, diferentes práticas de leitura vão sendo desenvolvidas, fomentando diversos perfis de leitores. Como o contexto social é mutante, aferimos que a leitura e suas práticas constituem um processo dinâmico e flexível, consequentemente, proporcionaram e proporcionam pluralidade de leitores ao longo dos tempos.

\subsubsection{A percepção dos leitores quanto às questões estruturais da Biblioteca Transcol}

A Biblioteca Transcol foi instituída com o intuito, a priori, de despertar nos usuários do sistema de transporte o gosto pela leitura, de forma que o tempo gasto nos terminais e nos ônibus fosse aproveitado em prol da leitura. $\mathrm{O}$ acervo das unidades é formado por obras de literatura, especificamente romances, sejam nacionais quanto estrangeiros. Analisando a percepção dos leitores a respeito da qualidade dos materiais disponibilizados no acervo dessas unidades, para 21 leitores $(65,7 \%)$, o material é de excelente qualidade, atendendo suas expectativas; logo, para onze leitores $(34,3 \%)$, os materiais são bons, porém recomendam que o acervo poderia ser mais diversificado (gráfico 9).

Gráfico 9-Qualidade dos materiais disponibilizados pelas bibliotecas 
Relatos de Pesquisa

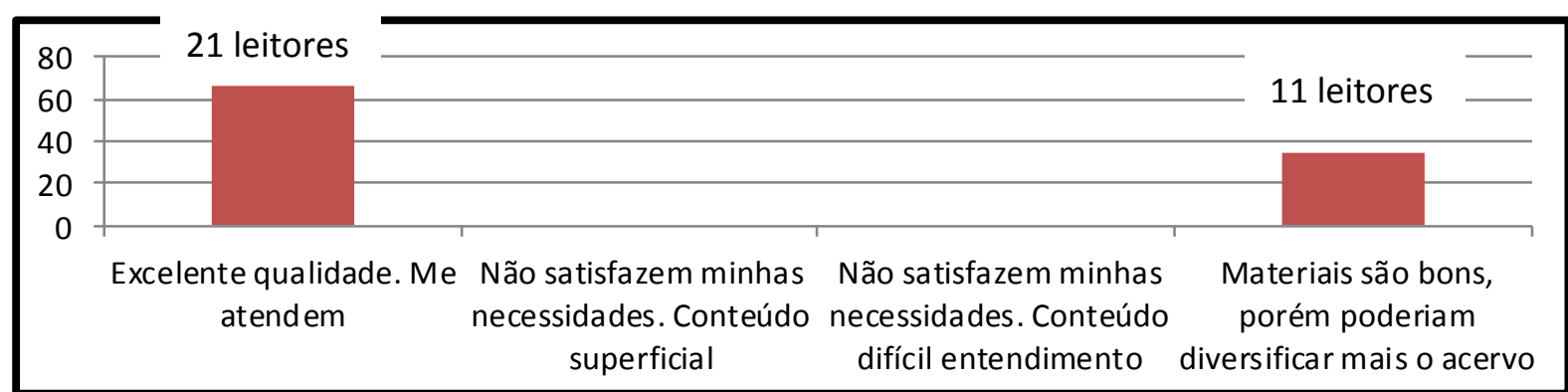

Fonte: dados da pesquisa (2016).

Por meio desses dados, percebe-se que, o acervo está atendendo as necessidades dos usuários. Alguns consideram como melhoria a diversificação do acervo. De qualquer forma, é preciso monitoramento por parte do bibliotecário, sendo indispensável que o profissional conheça muito bem todo o seu acervo e o perfil de seus usuários, possibilitando satisfação dos leitores e produção de conhecimento (DINIZ, 2011).
Quando indagados a respeito do que poderia ser feito para que a leitura fosse mais concretizada, 22 leitores $(68,75 \%)$ pensam que a unidade poderia oferecer mais materiais; dois leitores $(6,25 \%)$ sugerem a disponibilização de espaço com mesas e cadeiras; por fim, oito leitores $(25 \%)$ acham importante que o material emprestado tivesse um prazo mais estendido (gráfico 10).

Gráfico 10 - Opções adotadas pela biblioteca que poderiam viabilizar o hábito da leitura

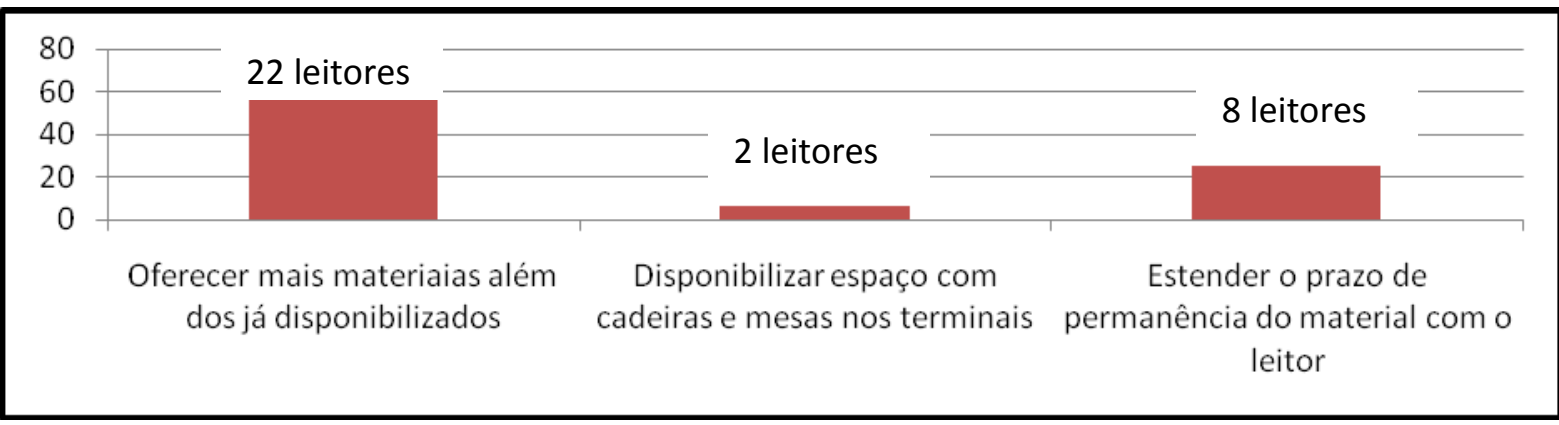

Fonte: dados da pesquisa (2016).

Nota-se que, na opinião dos leitores, a maioria considera como principal fator a ser pensado na tentativa de incentivar a prática da leitura é diversificar as coleções que formam o acervo. Esse resultado condiz com o que reza o PNLL ao dispor sobre a necessidade de ofertar livros em diferentes formatos e que atenda as necessidades do público servido.

As unidades existentes nos terminais possuem acervo composto por livros em estantes e alguns computadores para consulta ao acervo e para viabilizar acesso à internet. Não há disponibilização de espaço para leitura com cabines, mesas e cadeiras. Ao perguntar aos leitores sobre a montagem de um espaço para leitura, contendo mobiliário apropriado, 17 leitores $(53,1 \%)$ entendem que seria bom, pois aumentaria o poder de concentração; para seis leitores $(18,7 \%)$, o espaço seria bom, pois diminuiria problemas de postura, uma vez que usuários aguardam o transporte em pé; já para três leitores $(9,3 \%)$, esse espaço não ajudaria em nada, pois eles fazem as leituras em suas residências; outros seis leitores também disseram que não ajudaria, pois eles fazem as leituras nos ônibus (gráfico 11).

Gráfico 11 - Criação de espaços de leitura, com mesas e cadeiras, na biblioteca 
Relatos de Pesquisa

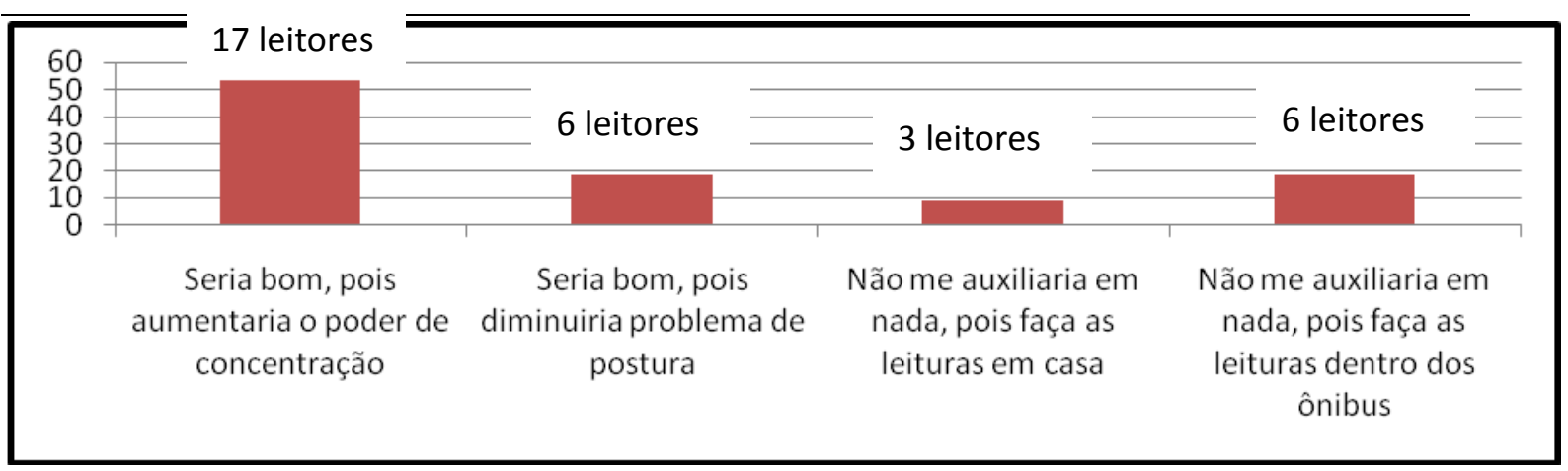

Fonte: dados da pesquisa (2016).

Percebe-se que a maioria considera a estruturação do espaço como viável. Assim, não basta apenas oferecer as fontes, é preciso também, disponibilizar um espaço adequado e agradável (BRASIL, 2011). Segundo Santa Anna, Gregório e Gerlin (2014), a fim de despertar o gosto e motivação dos leitores/educandos, faz-se imprescindível a estruturação de um espaço dinâmico, interativo e acolhedor, o que exige criatividade e inovação por parte dos profissionais responsáveis pelo gerenciamento do espaço.

\section{CONSIDERAÇÕES FINAIS}

O presente estudo apresentou algumas características da Biblioteca Transcol, as práticas de leitura realizadas, o perfil dos leitores e a percepção dos leitores quanto ao papel dessa unidade no fomento à leitura. Logo, o objetivo da pesquisa foi atendido. De modo geral, constatou-se ser uma ação válida a gestão desse projeto, uma vez que atende, em alguns aspectos, as recomendações do PNLL.

A partir dos dados e das informações teóricas analisadas nesta pesquisa, constatouse que o cenário que reveste o imaginário do leitor é diversificado, e a prática da leitura pode ser realizada em diferentes ambientes, não estando engessada unicamente nos espaços e instituições tradicionais, como nas residências, nas instituições escolares ou nas unidades de informação. $\mathrm{O}$ ato de leitura desperta no leitor a construção de novas habilidades e viabiliza a consumação do aprendizado, sem considerar o espaço, a posição, enfim, independente da maneira como a leitura é praticada.

De modo geral, o estudo aplicado a 32 leitores da Biblioteca Transcol demonstrou que, a grande maioria realiza as leituras em suas residências, com a finalidade de entretenimento. Essa preferência pode ser justificada pelo fato da grande maioria considerar inúmeros fatores ergonômicos que interferem no processo de leitura, como: barulho, luminosidade e postura em pé.

No que se refere às práticas de leituras oferecidas pela Biblioteca Transcol, em linhas gerais, constatou-se que a leitura desenvolvida na referida unidade constitui um processo dinâmico, mutante, plural e prazeroso, com práticas de leitura diversificadas, tendo o leitor diferentes comportamentos durante a consolidação do ato ler.

Com efeito, constatou-se, no que se refere aos aspectos voltados ao perfil do leitor, que os usuários das Bibliotecas Transcol leem diversos livros, tendo preferência por romances. Em linhas gerais, esses livros são lidos de forma individual e com rapidez, o que caracteriza as leituras como extensivas, no entanto, mesmo assim, os leitores não perdem a tendência contemplativa.

Os resultados obtidos a partir da percepção dos usuários quanto aos produtos $\mathrm{e}$ serviços prestados pela Biblioteca Transcol permitem afirmar que, de modo geral, os leitores estão satisfeitos e sendo despertados ao gosto e hábito pela leitura. Sugerem como melhoria a diversificação quanto às modalidades de livros ofertados e a construção de um espaço específico para acomodar os leitores.

Este estudo também demonstrou a viabilidade do projeto Biblioteca Transcol, até o momento, ao adotar práticas que fomentem a leitura em diferentes espaços sociais, atendendo às políticas públicas voltadas para a formação de leitores, assegurando $o$ exercício da cidadania. O contexto analisado na pesquisa viabiliza a formação de diferentes leitores, cujos objetivos ao praticar a leitura é 
aproveitar o tempo despendido ao se utilizar o transporte urbano na aquisição de novas informações oriundas com a prática da leitura.

Com o término desta pesquisa e com os bons resultados obtidos a partir da Biblioteca Transcol, bem como diante das recomendações propostas pelos planos governamentais a respeito da leitura, recomenda-se a elaboração de outros projetos dessa natureza, em que a biblioteca seja vista como um espaço sem fronteiras, no que diz respeito ao fomento à leitura. Sugerem-se pesquisas e projetos que proponham, por exemplo, a inserção dos espaços de leitura em outros ambientes abertos de grande circulação, tais como na estação ferroviária, no aeroporto e nos terminais rodoviários intermunicipais existentes na região da Grande Vitória. A leitura não pode parar, pois se trata de um processo transformador da realidade

Recebido em: 20/01/2017

Aceito em definitivo em: 29/05/2017

\title{
LIBRARIES WITHOUT BORDERS IN THE PROMOTION OF READING: THE CASE OF THE TRANSCOL LIBRARY
}

\begin{abstract}
This study comprises the final results of a research, whose subject contemplates the mission of transcendence of libraries with regard to the promotion of reading. It aims to present the Transcol Library Project, demonstrating the supply of informational material made available in high traffic road terminals and available to users who use the urban transportation system of the Vitoria metropolitan region, Espirito Santo. Methodologically, through the observation and application of a questionnaire, the structures and collections of this unit are presented, reading practices and readers' profile are analyzed, as well as the perception of the users of these spaces as to the material provided and the environmental conditions For reading. It was concluded that the reading developed in said unit constitutes a dynamic, mutant, plural and pleasurable process, with diverse reading practices, the reader having different behaviors during the consolidation of reading. It was found that the readings are characterized as extensive, however, even so, the readers do not lose the contemplative tendency. It has been realized that the readers are satisfied and being awakened to the taste and habit by the reading. The interviewees suggested as an improvement the diversification regarding the modalities of books offered and the construction of a specific space to accommodate the readers. It is recommended that this project be extended to other transportation stations in the region, so as to enable an increasingly reading society.
\end{abstract}

Keywords: Reading. Reading Practices. Transcol Library Project. Reader Profile - Transcol Library. Librarian - Social Role.

REFERÊNCIAS
BARRETO, Angela Maria. Os espaços de leitura. Comunicação e Educação, v. 12, n. 1, p. 41-53, jan./abr. 2007. Disponível em: < 
http://www.revistas.usp.br/comueduc/article/v iew/37618>. Acesso em: 14 fev. 2016.

BRASIL. Decreto n. ${ }^{\mathbf{0}} \mathbf{7 . 5 5 9}$, de $1 .^{\circ} \mathrm{de}$ setembro de 2011. Dispõe sobre o Plano Nacional do Livro e da Leitura (PNLL) e dá outras providências. Disponível em: < http://www.planalto.gov.br/c civil_ 03/_ato2011-2014/2011/decreto/d7559.htm>. Acesso em: 12 fev. 2014.

BRITO, Danielle Santos de. A importância da leitura na formação social do indivíduo.

Revela, Faculdade Dom Domênico, Guarujá, ano 4, n. 8, jun./2010. Disponível em: < http://www.fals.com.br /revela12/Artigo4_ed08.pdf $>$. Acesso em: 12 fev. 2014.

CALDIN, Clarice Fortkamp. Reflexões acerca do papel do bibliotecário de biblioteca escolar. Revista ACB, Florianópolis, v. 10, n. 2, p. 163-168, 2005. Disponível em: < http://revista.acbsc.org.br/racb/article/view/43 1/549>. Acesso em: 12 fev. 2016.

CHARTIER, Roger. Do códice ao monitor: a trajetória do escrito. Estudos Avançados, v. 8, n. 21, p. 185-199, 1994. Disponível em: <http://www.scielo.br/scielo.php?script=sci_a rttext \&pi d=S0103-40141994000200012>. Acesso em: 12 dez. 2015.

CHARTIER, R.; CAVALLO, G. (Org.) História da leitura no mundo ocidental. São Paulo: Ática, 1998. (Coleção Múltiplas Escritas).

CHARTIER, Roger; LEBRUN, Jean. A aventura do livro: do leitor ao navegador: conversações com Jean Lebrun. São Paulo: Ed. da UNESP, 1998.

DINIZ, Jaiene Gomes; et al. O bibliotecário como agente incentivador da leitura: apresentação do projeto de extensão Doutores da Leitura. In: ENCONTRO REGIONAL DE ESTUDANTES DE BIBLIOTECONOMIA, DOCUMENTAÇÃO, CIÊNCIA DA INFORMAÇÃO E GESTÃO DA INFORMAÇÃO, 14, Anais eletrônicos. São Luiz: Universidade Federal do Maranhão, 16 a 22 de janeiro de 2011.
HILLESHEIM, Betina et al. Leitura: entre leitor e texto. Fractal: Revista de Psicologia, v. 23, n. 2, p. 305-316, maio/ago. 2011. Disponível em: < http://www.uff.br/periodicoshumanas/index.p hp/Fractal/article/view/398/521>. Acesso em: 16 fev. 2016.

MARINHO, Raimunda Ramos. Leitura: um caminho para a cidadania. Transinformação, Campinas, v. 5, n. 1,2,3, jan./dez. 1993. Disponível em: < http://periodicos.puccampinas.edu.br/seer/index.php/transinfo/arti cle/viewFile/1650/1621>. Acesso em: 14 fev. 2016.

PITZ, Juliana; SOUZA, Vanessa Aline; BOSO, Augiza Karla. O papel do bibliotecário escolar na formação do leitor. Revista ACB: Biblioteconomia em Santa Catarina, Florianópolis, v.16, n.2, p. 405-418, jul./dez., 2011. Disponível em: < http://revista.acbsc.org.br/racb/article/view/73 6/pdf_59>. Acesso em: 14 fev. 2016.

ROSA, Flávia Goullart Mota Garcia; ODDONE, Nanci. Políticas públicas para o livro, leitura e biblioteca. Ciência da Informação, Brasília, v. 35, n. 3, p.183-193, set./dez. 2006.

SANTAELLA, Lucia. Navegar no ciberespaço: o perfil do leitor imersivo. São Paulo: Paullus, 2004.

universid, Jorge; PEREIRA, Gleice. Os suportes de informação e suas interferências na formação do leitor. Revista Linha Mestra, n.24, jan./jul. 2014. Disponível em: https://linhamestra24.files.wordpress.com/201 4/07/linha_mestra_24_19_cole_06_comunica coes_ilsa_josuelene.pdf. Acesso em: 14 fev. 2016.

SANTA ANNA, Jorge; GREGÓRIO, Elaine; GERLIN, Meri Nadia. Atuação bibliotecária além da biblioteca: o espaço de leitura do Hospital Universitário Cassiano Antônio de Moraes (HUCAM). Revista ACB: Biblioteconomia em Santa Catarina, Florianópolis, v.19, n.1, p. 77-88, jan./jun., 2014.

SCLIAR-CABRAL, Leonor. Processamento da leitura: recentes avanços das 
neurociências. In: COSTA, Jorge Campos da; PEREIRA, Vera (Org.). Processamento da leitura: recentes avanços das neurociências. Porto Alegre: EDIPUCRS, 2009, p. 48-58.

UNIVERSIDADE PARA TODOS. Projeto Biblioteca Transcol. 2014. Disponível em: < http://bibliotecatranscol.blogspot.com.br/>. Acesso em: 16 fev. 2015.

${ }^{1}$ Os resultados parciais deste estudo foram apresentados no XI Encontro de Diretores e X Encontro de Docentes das Escolas de Biblioteconomia e Ciência da Informação do MERCOSUL (EBCIM), evento ocorrido em 2016, na cidade de Belo Horizonte.

${ }^{2}$ Os resultados referentes às práticas de leitura e perfil do leitor da Biblioteca Transcol foram apresentados, de forma preliminar, ao $19 .^{\circ}$ Congresso de Leitura (COLE), ocorrido em 2014, na cidade de Campinas/SP.

${ }^{3}$ Os resultados referentes às percepções dos usuários quanto à Biblioteca Transcol foram apresentados, de forma preliminar, ao $26^{\circ}$ Congresso de Biblioteconomia e Documentação (CBBD), ocorrido em 2015, na cidade de São Paulo/SP. 